\title{
The effect of atropine in preventing catheter-related pain and discomfort in patients undergoing transurethral resection due to bladder tumor; prospective randomized, controlled study
}

\author{
Yeliz Şahiner ${ }^{1}$, Özgür Yağan ${ }^{1}$, Arzu Akdağlı Ekici ${ }^{1}$, Musa Ekici $^{2}$, and Emre Demir ${ }^{3}$ \\ 'Department of Anesthesiology and Reanimation, Erol Olçok Training and Research Hospital, Hitit University Faculty of Medicine, Çorum, Turkey \\ 2Department of Urology, Erol Olçok Training and Research Hospital, Hitit University Faculty of Medicine, C,orum, Turkey \\ ${ }^{3}$ Department of Biostatistics, Hitit University Faculty of Medicine, C,orum, Turkey
}

Received October 21, 2019

Revised December 11, 2019

Accepted December 16, 2019

\section{Correspondence}

Yeliz Şahiner

Department of Anesthesiology and Reanimation, Erol Olçok Training and Research Hospital, Hitit University Faculty of Medicine, Inonu Cad, No. 176, 19040 Çorum, Turkey

Tel: +90-364-2221100

Fax: +90-364-2193000

E-mail: yelizsahiner@gmail.com
Background: Catheter-related bladder discomfort (CRBD) has been observed in many patients undergoing a urethral catheterization. CRBD may be so severe that the patients require additional analgesics. Muscarinic receptors are involved in the mechanism of CRBD. The aim of this study is to determine the effects of the antimuscarinic properties of atropine, which is frequently used in current practice on CRBD, by comparing it with sugammadex which has no antimuscarinic effects. Methods: Sixty patients selected for transurethral resection due to bladder tumors were randomized into 2 groups: an atropine group and a sugammadex group, with no antimuscarinic effect. The patients were given rocuronium $(0.6 \mathrm{mg} / \mathrm{kg})$ as a neuromuscular-blocker. In addition to the frequency and severity of CRBD postoperatively at $0,1,6,12$, and 24 hours, postoperative numeric rating scale (NRS) scores, and postoperative nausea and vomiting were examined.

Results: The incidence of CRBD was significantly lower in the atropine group in all postoperative measurements. The score was found to be significantly lower in the atropine group when NRS measurements were performed at all time periods $(P<$ $0.01)$. There was no difference between the groups in terms of nausea and vomiting $(P>0.05)$.

Conclusions: Atropine is a cheap, easy-to-access, safe-to-use drug for reducing CRBD symptoms, without any observed adverse effects. Since it not only reduces CRBD symptoms but also has a positive effect on postoperative pain, it can be used safely to increase patient comfort in patients receiving general anesthesia and a urinary catheter.

Key Words: Atropine; Clinical Study; General Anesthesia; Muscarinic Antagonists; Pain Measurement; Patient Comfort; Postoperative Pain; Sugammadex; Urinary Bladder Neoplasms; Urinary Catheters.

\section{INTRODUCTION}

It is a routine procedure to perform a postoperative catheter on patients who have been operated on due to a blad- der tumor. Catheter-related bladder discomfort (CRBD) is often observed in patients with postoperative pain [1]. The incidence of CRBD ranges from $47 \%$ to $95 \%$ during the post-operative period in patients with urinary catheter- (c) This is an open-access article distributed under the terms of the Creative Commons Attribution Non-Commercial License (http://creativecommons.org/licenses/by-nc/4.0/), which permits unrestricted non-commercial use, distribution, and reproduction in any medium, provided the original work is properly cited.

(C) The Korean Pain Society, 2020
Author contributions: Yeliz Şahiner: Writing/manuscript preparation; Özgür Yağan: Study conception; Arzu Akdağlı Ekici: Investigation; Musa Ekici: Investigation; Emre Demir: Methodology. 
ization [2]. This pain negatively affects patient comfort during the postoperative period and also leads to the additional analgesic need for clinical follow-up. CRBD is often expressed by patients as a burning sensation, pain, and discomfort in the suprapubic region [3]. This feeling of discomfort may be severe enough to lead the patient to delirium symptoms during the postoperative period [4]. Symptoms often resemble overactive bladder syndrome.

There have been treatment approaches with antimuscarinic drugs for this condition, which develops as a result of activation of muscarinic 3 receptors (M3) in the bladder [5]. Antimuscarinic agents (such as propantheline bromide, hyoscyamine, and oxybutynin) and muscarinic receptor antagonists (such as darifenacin, solifenacin, and trospium) are used for the suppression of detrusor activity $[1,2]$. As it is known, antimuscarinic drugs have various side effects such as dry mouth, sedation, and severe nausea and vomiting, so in current practice, it is not usually the preferred treatment of CRBD during the postoperative period.

Atropine is a popular anticholinergic agent used to reverse the effect of nondepolarizing muscle relaxant agents and has various effects on muscarinic receptors. Studies have shown that atropine is effective on M2 and M3 receptors [6]. Atropine is the prototype of anticholinergic agents and has been used in operating room conditions for years in reversing the effect of nondepolarizing neuromuscular blocking agents due to its non-selective inhibitory properties on muscarinic receptors, as well as being a safe, inexpensive and easily accessible agent.

Sugammadex (Bridion; Patheon, Greenville, NC) is a non-antimuscarinic agent that specifically binds rocuronium, a neuromuscular blocker, in plasma, and is commonly used in general anesthesia. Due to its fast reverse effect, it is frequently applied in current practice [7].

This study was planned to show the effects of atropine administration in minimizing the risk of CRBD in the postoperative period for patients who underwent surgery due to bladder tumor.

\section{MATERIALS AND METHODS}

Following the approval of the Ethics Committee of the Hitit University Faculty of Medicine (date: 07/07/2017, issue: 2017/56), this prospective, randomized, double blind controlled clinical study was started. All patients were given detailed information about the study, and their written informed consent was taken.

Patients who were admitted to the Erol Olçok Training and Research Hospital's urology clinic for bladder tumors between September 2017 and December 2018, and who were planned for elective transurethral resection, were included in the study.

Preoperative anesthesia evaluation included individuals aged 18-80 years with American Society of Anesthesiologists-Physical Status (ASA-PS) classification I-III. Patients with bladder outflow obstruction, an overactive bladder, end-stage kidney or liver disease, a neurogenic bladder, heart failure, arrhythmia, morbid obesity, lung disease, pregnancy, lactation, psychiatric disorders, or insufficient mental capacity were not included in the study. Patients who wanted to leave at any stage of the study and did not sign a consent form for the study were excluded from the study. Participants were assigned to groups using a table randomization method. The patients were divided into two groups: the atropine group (group $1, n=30$ ) and sugammadex group (group $2, \mathrm{n}=30$ ). Thus, by comparing atropine acting on the muscarinic receptors in the bladder, and sugammadex, which has no effect on these receptors, it was investigated whether atropine would actually have an effect on CRBD.

All patients were given detailed information about CRBD and the pain rating method to be used in the postoperative period. The numeric rating scale (NRS) was used to evaluate postoperative pain. Patients' NRS scores showing postoperative surgical pain were recorded at $0,1,6,12$, and 24 hours. To evaluate CRBD, patients were asked to rate their feeling of discomfort between 0 to 3 (0: none, 1 : low, 2: medium, 3: severe). In addition, the postoperative nausea and vomiting (PONV) scale was used to evaluate the PONV of patients. In postopereative visits, patients were asked about dry mouth, blurred vision, and flushing. Diclofenac Na two times per day was administered intramuscularly for analgesia in the postoperative period. It was evaluated whether there were additional analgesic requirements during postoperative follow-up.

All patients' age, sex, body mass index, anesthesia time, surgical procedure duration, complications, and side effects were recorded in the case report form.

Patients were not given premedication, and electrocardiogram, noninvasive blood pressure, and peripheral oxygen saturation were monitored after they were taken to the operation table. The intravenous (IV) vascular access was opened to the upper surface of the left hand with a $20 \mathrm{G}$ venous cannula, and administration of $10 \mathrm{~mL} / \mathrm{kg}$ Ringer's lactate solution was begun. General anesthesia was initiated with $2.5 \mathrm{mg} / \mathrm{kg}$ of propofol and $2 \mathrm{ng} / \mathrm{mL}$ controlled infusion of remifentanil. Following $0.6 \mathrm{mg} / \mathrm{kg}$ rocuronium, the patients were given mask ventilation for 3 minutes, then a number-I laryngeal mask (Intersurgical Ltd., Wokingham, UK) that appropriates for their weight was placed. Also, a 2\% sevoflurane (Sevorane; Aesica Queenborough Ltd., Queenborough, UK), 50\% oxygen, 
and $50 \%$ air mixture and $0.2-0.7 \mu \mathrm{g} / \mathrm{kg} / \mathrm{min}$ remifentanil infusion were performed for anesthesia maintenance. At the end of the surgery, inhalers and IV anesthetic agents were discontinued. For the antagonization of neuromuscular blockade, patients in the group 1 were given $15 \mu \mathrm{g} /$ $\mathrm{kg}$ of atropine, $25 \mu \mathrm{g} / \mathrm{kg}$ of neostigmine, and group 2 were given $4 \mathrm{mg} / \mathrm{kg}$ of sugammadex IV with a total volume of 10 $\mathrm{mL}$. At the end of the procedure, all patients were given 50 $\mathrm{mg} / 2 \mathrm{~mL}$ dexketoprofen trometamol IV as an analgesic.

The patients were operated on by the same senior surgeon. The catheterization of the patients and the size selection of the catheter were made by the surgeon. Following the end of the operation, the surgeon irrigated the catheter so that no particles or blood clots remained. The urinary catheter was taped to the inner side of the patient's thigh so that it would not be strained. The patients were taken to the recovery room at the end of the procedure. Postoperative 0 hour NRS and CRBD assessment were recorded by the wake-up nurse who was blind to the groups, while other measurements were recorded by the service nurse who was also blind to the groups. Patients were asked to score between 0 and 3 for their feeling of discomfort (0: none, 1: little, 2: moderate, 3: severe) to evaluate CRBD scores during the postoperative period. Surgeons and clinical nurses who measured the post-operative NRS scores, PONV, and CRBD severity were also left blind to the groups. All records were written into the case report form.

\section{Statistical analysis}

Before the study, the sample size for the groups was calculated by power analysis (power $=0.80$ ). PASS (power analysis and sample size software; NCSS, LLC, Kaysville, UT) package software was used for power analysis (version 11 trial version). In order to calculate the estimated number of sample of groups, previous reference studies were examined and, the hypothesis means for the two groups were determined as 6 and 5, respectively, and the standard deviation was 1.5 with an equal number of subjects in each group. Alpha $(\alpha)$ was accepted as $0.05(95 \%$ significance level). As a result of the power analysis, the sample number was determined to be 60,30 for each group, with an effect size of 0.373 and $81 \%$ power $(0.81)$.

In this study, statistical analyses were conducted using the SPSS ver. 22.0 (IBM Corp., Armonk, NY, and licensed to Hitit University) package software. Descriptive statistics were presented as mean \pm standard deviation for the normally distributed continuous data, as a median for the non-normal continuous data and ordinal data, and as a number-percentage (\%) for the categorical data. The distribution of normality was examined by the Kolmogorov-
Smirnov and Shapiro-Wilk tests. The homogeneity of the variances was examined by Levene's test. The independent sample $t$-test (for data showing the normal distribution in mean comparisons), and Mann-Whitney $U$-test (for data that did not show normal distribution) was used for comparison of two independent samples (for continuous variables). A chi-square test was used for nominal variables. Statistical significance was accepted as $P<0.05$.

\section{RESULTS}

A total of 60 patients were included in the study, consisting of 30 patients in each group. There was no morbidity or mortality during the study. All the involved patients were included in the study.

The patients who participated in the study were homogeneously distributed to both groups in terms of age, sex, ASA score, and body mass index, and there was no difference between the groups $(P=0.150, P=1.000, P=0.290, P$ $=0.462$, respectively). It was found that the male sex was higher in both of the study groups. In the comparison of the duration of anesthesia of both groups, it was observed that the duration of anesthesia in the sugammadex group was significantly shorter $(P=0.004)$, and there was no difference in surgical duration between the groups $(P=0.150)$. At the end of the surgery, it was observed that there was no

Table 1. Characteristics of the Patients

\begin{tabular}{|c|c|c|c|}
\hline Characteristic & $\begin{array}{l}\text { Group } 1 \\
(n=30)\end{array}$ & $\begin{array}{l}\text { Group } 2 \\
(n=30)\end{array}$ & $P$ value \\
\hline Age (yr) & $59.7 \pm 2.8$ & $58.7 \pm 2.5$ & 0.150 \\
\hline Sex & & & 1.000 \\
\hline M & $25(83.3)$ & $25(83.3)$ & \\
\hline $\mathrm{F}$ & $5(16.7)$ & $5(16.7)$ & \\
\hline ASA-PS & & & 0.290 \\
\hline I & $3(10.0)$ & $4(13.3)$ & \\
\hline$\|$ & $21(70.0)$ & $11(36.7)$ & \\
\hline III & $6(20.0)$ & $15(50.0)$ & \\
\hline Body mass Index $\left(\mathrm{kg} / \mathrm{m}^{2}\right)$ & $27.9 \pm 3.9$ & $27.2 \pm 3.4$ & 0.462 \\
\hline Duration of anesthesia (min) & $53.3 \pm 21.5$ & $38.0 \pm 17.8$ & 0.004 \\
\hline Duration of surgery (min) & $41.5 \pm 18.8$ & $30.7 \pm 14.6$ & 0.150 \\
\hline $\begin{array}{l}\text { Dose of intraoperative } \\
\text { remifentanil }(\mu \mathrm{g} / \mathrm{kg} / \mathrm{hr})\end{array}$ & $7.3 \pm 5.1$ & $7.1 \pm 4.9$ & 0.877 \\
\hline Urinary catheter size & & & 1.000 \\
\hline$<18 \mathrm{Fr}$ & 1 & 0 & \\
\hline $18 \mathrm{Fr}$ & 4 & 5 & \\
\hline $19 \mathrm{Fr}$ & 14 & 13 & \\
\hline $20 \mathrm{Fr}$ & 11 & 12 & \\
\hline
\end{tabular}

Values are presented as mean \pm standard deviation, number (\%), or number only.

Group 1: the atropine group, group 2: sugammadex group, ASA-PS: American Society of Anesthesiologists-Physical Status. 
Table 2. NRS Scores of the Patients

\begin{tabular}{cccc}
\hline $\begin{array}{c}\text { Postoperative } \\
\text { NRS score }\end{array}$ & $\begin{array}{c}\text { Group 1 } \\
(\mathrm{n}=30)\end{array}$ & $\begin{array}{c}\text { Group 2 } \\
(\mathrm{n}=30)\end{array}$ & $P$ value \\
\hline $0 \mathrm{hr}$ & $2.0 \pm 0.2$ & $5.0 \pm 0.3$ & $<0.001$ \\
$1 \mathrm{hr}$ & $1.2 \pm 0.2$ & $3.9 \pm 0.3$ & $<0.001$ \\
$6 \mathrm{hr}$ & $0.8 \pm 0.2$ & $3.2 \pm 0.2$ & $<0.001$ \\
$12 \mathrm{hr}$ & $0.3 \pm 0.1$ & $2.6 \pm 0.2$ & $<0.001$ \\
$24 \mathrm{hr}$ & $0.0 \pm 0.0$ & $1.7 \pm 0.1$ & $<0.001$ \\
\hline
\end{tabular}

Values are presented as mean \pm standard deviation.

NRS: numerical rating scale, group 1: the atropine group, group 2: sugammadex group.

Table 3. Incidence and Severity of CRBD in Patients Undergoing Transurethral Resection of the Bladder Tumor

\begin{tabular}{|c|c|c|c|}
\hline $\begin{array}{l}\text { Catheter related } \\
\text { bladder discomfort }\end{array}$ & $\begin{array}{l}\text { Group } 1 \\
(n=30)\end{array}$ & $\begin{array}{l}\text { Group } 2 \\
(n=30)\end{array}$ & $P$ value \\
\hline \multicolumn{4}{|l|}{ Postoperative hr } \\
\hline \multicolumn{4}{|l|}{$0 \mathrm{hr}$} \\
\hline Incidence & $27(90.0)$ & $30(100)$ & \\
\hline Severity & & & $<0.001$ \\
\hline Mild & $12(40.0)$ & $1(3.3)$ & \\
\hline Moderate & $15(50.0)$ & $15(50.0)$ & \\
\hline Severe & $0(0)$ & $14(46.7)$ & \\
\hline \multicolumn{4}{|l|}{$1 \mathrm{hr}$} \\
\hline Incidence & $21(70.0)$ & 30 (100) & \\
\hline Severity & & & $<0.001$ \\
\hline Mild & 19 (63.3) & $2(6.7)$ & \\
\hline Moderate & $2(6.7)$ & $17(56.7)$ & \\
\hline Severe & $0(0)$ & $11(36.7)$ & \\
\hline \multicolumn{4}{|l|}{$6 \mathrm{hr}$} \\
\hline Incidence & $12(40.0)$ & 30 (100) & \\
\hline Severity & & & $<0.001$ \\
\hline Mild & $12(40.0)$ & $9(30.0)$ & \\
\hline Moderate & $0(0)$ & $19(63.3)$ & \\
\hline Severe & $0(0)$ & $2(6.7)$ & \\
\hline \multicolumn{4}{|l|}{$12 \mathrm{hr}$} \\
\hline Incidence & $3(10.0)$ & $29(96.7)$ & \\
\hline Severity & & & $<0.001$ \\
\hline Mild & $3(10.0)$ & $22(73.3)$ & \\
\hline Moderate & $0(0)$ & 7 (23.3) & \\
\hline Severe & $0(0)$ & $0(0)$ & \\
\hline \multicolumn{4}{|l|}{$24 \mathrm{hr}$} \\
\hline Incidence & $0(0)$ & $24(80.0)$ & \\
\hline Severity & & & $<0.001$ \\
\hline Mild & $0(0)$ & $18(60.0)$ & \\
\hline Moderate & $0(0)$ & $6(20.0)$ & \\
\hline Severe & $0(0)$ & $0(0)$ & \\
\hline
\end{tabular}

Values are presented as number (\%).

CRBD: catheter-related bladder discomfort, group 1: the atropine group, group 2: sugammadex group.

difference between the groups in terms of the size of the urinary catheter $(P=1.00)$. The demographic characteristics of the patients are shown in Table 1.
Table 4. Postoperative Nause and Vomiting (PONV)

\begin{tabular}{lccc}
\hline \multicolumn{1}{c}{ PONV } & $\begin{array}{c}\text { Group 1 } \\
(\mathrm{n}=30)\end{array}$ & $\begin{array}{c}\text { Group 2 } \\
(\mathrm{n}=30)\end{array}$ & P value \\
\hline $\begin{array}{l}\text { Postopeartive 0 hr } \\
\quad \text { None }\end{array}$ & $27(90.0)$ & $27(90.0)$ & 1.000 \\
$\quad$ Exist & $3(10.0)$ & $3(10.0)$ & \\
Postopeartive 1 hr & & & 1.000 \\
$\quad$ None & $30(100)$ & $29(96.7)$ & \\
$\quad$ Exist & $0(0)$ & $1(3.3)$ & \\
Postopeartive 6 hr & & & 1.000 \\
$\quad$ None & $28(93.3)$ & $29(96.7)$ & \\
$\quad$ Exist & $2(6.7)$ & $1(3.3)$ & 1.000 \\
Postopeartive 12 hr & & & \\
$\quad$ None & $30(100)$ & $30(100)$ & \\
$\quad$ Exist & $0(0)$ & $0(0)$ & \\
\hline
\end{tabular}

Values are presented as number (\%).

Group 1: the atropine group, group 2: sugammadex group.

The surgical pain of patients in the postoperative period was evaluated by medical personnel blind to the groups at $0,1,6,12$, and 24 hours (Table 2). Detailed preoperative information was given to the patients to distinguish between surgery pain and CRBD. The pain scores associated with surgery were significantly lower in the atropine group at all measurement times $(P<0.001)$.

Patients were asked to score between 0 and 3 for the feeling of discomfort (0: none, 1 : little, 2: moderate, 3: severe) to evaluate CRBD scores during the postoperative period. CRBD frequency was seen less in group 1 in all measurements. In addition, the severity of CRBD was significantly lower in group 1 in all measurements. Also, CRBD was not seen in group 1 in 24th-hour measurements (Table 3).

When PONV was evaluated, no significant difference was found between the two groups $(P=1.000$; Table 4$)$. None of the patients had symptoms such as dry mouth, blurred vision, or flushing that would cause discomfort. None of the patients needed additional analgesics.

\section{DISCUSSION}

As a result of this study, it was determined that atropine, which is routinely used in general anesthesia, reduces the incidence of CRBD after surgery in patients undergoing transurethral intervention for bladder tumor. In order to clearly demonstrate the effect of atropine, it was compared with sugammadex, which has no effect on the muscarinic receptors.

CRBD poses a major problem in patients undergoing general anesthesia and urinary catheter [8]. CRBD is often one of the biggest problems in the patient's recovery room and causes agitation to a great extent $[1,4,8]$. With this agi- 
tation, since the patients are not fully conscious yet, they may cause urethral injuries and unwanted complications that may require re-intervention while they attempt to get rid of the catheter [9]. Therefore, prevention of CRBD will not only increase patient comfort but also provide protection from many complications such as the development of bleeding, injury, and urethral stenosis.

Data from the study showed that atropine both reduced the incidence of CRBD and diminished the severity of existing symptoms at all assessment times. Due to its effectiveness, almost no signs of CRBD were observed in any patient after the postoperative 12th hour. This prevented both unnecessary drug use and side effects that might occur due to the drugs. In their prospective randomized clinical trial for CRBD, Kim et al. [5] compared the effects of glycopyrrolate and atropine, and ultimately found that atropine was less effective. Although atropine was found to be less effective in Kim et al.'s study, they showed that very few patients had CRBD symptoms after the postoperative 6 th hour and that the severity was minimal in patients with symptoms.

CRBD was more observed in group 2 in terms of both incidence and severity. The postoperative 24 th hour evaluation revealed that CRBD symptoms persisted in $80 \%$ of patients in the sugammadex group. In light of these results, it appears that muscarinic receptor blockade plays an important role in CRBD management.

Studies have reported that atropine administration would not be the first choice for the treatment of CRBD by mentioning various side effects, such as visual impairment, dry mouth, and flushing, due to its anticholinergic effects in the postoperative period [5,10]. In this study, no anticholinergic side effects were observed in either group.

In this study, when anesthesia durations were evaluated, it was determined that the group 2 had significantly less duration of anesthesia. This is because sugammadex removes the effect of rocuronium (Esmeron; Merck Sharp Dohme ilaçları Ltd., ìstanbul, Turkey) very quickly and speeds up the patient's awakening. Although the difference in the duration of anesthesia between the groups was determined, no length of anesthesia was determined to cause extra complications in the atropine group. There was no significant difference between the groups in terms of surgical duration.

Interestingly, NRS scores assessing the patients' postoperative pain were significantly lower in group 1 at all measurement times (Table 2). Although atropine has no analgesic effect, and this significant difference in NRS scores is actually thought to distinguish the patient's surgery pain from CRBD, it is conceivable that the suprapubic area discomfort is actually caused by CRBD. As a result, whether this is due to surgery pain or whether the patient confuses the CRBD symptom with surgery pain, the eligibility of this drug in routine application is promising because the effect of atropine on the muscarinic receptors made the patients in group 1 more likely to experience postoperative comfort, so it does not require additional analgesics and shows no side effects.

In the evaluation of the patients in terms of PONV, there was no significant difference in both clinical and statistical aspects for both groups. Anticholinergic agents have long been known to decrease opioid-related nausea and vomiting, although their narrow therapeutic range and inconvenient route of administration (typically transdermal) have limited their application [11]. Anticholinergic agents are thought to act via the inhibition of muscarinic receptors in several regions of the medulla oblongata, which are implicated with nausea and vomiting generation; In addition to the chemoreceptor trigger zone, these receptors are particularly concentrated in, but not limited to the nucleus tractus solitarius. Cholinergic receptors have been typically associated with motion sickness, but cholinergic agonists such as neostigmine have been shown to increase the incidence of PONV, especially when injected intrathecally [12]. Although neostigmine was administered during anesthesia in group 1 , there was no difference compared to group 2 during the postoperative period, which makes cheap and easily accessible atropine a good choice for reducing CRBD symptoms as well as preventing nausea and vomiting. In the same way, patients did not complain of anticholinergic symptoms such as dry mouth, vision impairment, or flushing during the post-operative period, which can be explained by the arrangement of the appropriate dose of medication.

Zhou et al. [13] provided visual training to reduce CRBD in patients undergoing elective colon-rectum surgery, and in their prospective randomized study, they ultimately achieved positive results in patients receiving the training. In this study, detailed information about CRBD, although not visual, was given to patients during the preoperative period, which may have increased patient compliance and ensured that patients were not afraid of CRBD. Information may have ensured that almost no patients had severe CRBD in the postoperative 24th hour and that the severity of those seen in group 2 was minimal.

It is very important to control patient's postoperative pain. Many methods have been tried to reduce pain after open or laparoscopic surgery. Hwang et al. [14] investigated patient controlled analgesia effectiveness after laparoscopic radical prostatectomy, and showed better postoperative analgesia and greater patient satisfaction than IV analgesia. All studies in the literature are examining better analgesia control with minimal drug consumption and side effects. Therefore, we investigated the effects 
of these two commonly used anesthetics drugs in order to deal with a pain problem such as CRBD, without using any additional analgesics.

Although CRBD is seen very frequently after urological interventions, it may occur in many patients who receive general anesthesia and have a urinary catheter [8]. This issue has been addressed by many researchers $[1,10]$. Zhang et al. [2] investigated the protective effects of dezocine on CRBD in patients who underwent general anesthesia and catheterization in their clinical research, and reported positive results. Many agents with antimuscarinic effects are open to research and the side effects of each drug tried should be considered. The use of atropine, which is easy to access and cost-effective, which we can use almost routinely in general anesthesia applications, can be a great advantage compared to other drugs. Kim et al. [5] suggested in a study that CRBD can be seen in approximately $10 \%$ of patients receiving general anesthesia, and that this situation should be tackled with good pain control performed postoperatively. In our study, it was found that the incidence of postoperative CRBD, and the severity of developing CRBD, decreased only by the administration of atropine. In addition, there was no need for additional analgesics in any of the patients except for the postoperative analgesia protocol.

Consequently, atropine is a drug that can be safely used to reduce postoperative CRBD symptoms. Not only does it reduce CRBD symptoms, but it prevents PONV, and is cheap, easily accessible, and safe, which suggest that it is a preferable agent in routine practice.

\section{ACKNOWLEDGMENTS}

Authors thank to head of Surgical Intensive Care Unit, Hitit University Faculty of Medicine, associate professor of Surgery, Dr. Ibrahim Tayfun Șahiner for his contribution to postoperative follow-up, processing, and editing of patients' data.

\section{CONFLICT OF INTEREST}

No potential conflict of interest relevant to this article was reported.

\section{FUNDING}

No funding to declare.

\section{ORCID}

Yeliz Şahiner, https://orcid.org/0000-0002-5377-3870

Özgür Yağan, https://orcid.org/0000-0003-1596-1421

Arzu Akdağlı Ekici, https://orcid.org/0000-0001-7219-3145

Musa Ekici, https://orcid.org/0000-0002-9155-4126

Emre Demir, https://orcid.org/0000-0002-3834-3864

\section{REFERENCES}

1. Bai Y, Wang X, Li X, Pu C, Yuan H, Tang Y, et al. Management of catheter-related bladder discomfort in patients who underwent elective surgery. J Endourol 2015; 29: 640-9.

2. Zhang GF, Guo J, Qiu LL, Li SM, Zheng M, Xia JY, et al. Effects of dezocine for the prevention of postoperative catheterrelated bladder discomfort: a prospective randomized trial. Drug Des Devel Ther 2019; 13: 1281-8.

3. Kim DH, Park JY, Yu J, Lee SA, Park S, Hwang JH, et al. Intravenous lidocaine for the prevention of postoperative catheter-related bladder discomfort in male patients undergoing transurethral resection of bladder tumors: a randomized, double-blind, controlled trial. Anesth Analg 2019. doi: 10.1213/ANE.0000000000004405.

4. Kim HC, Kim E, Jeon YT, Hwang JW, Lim YJ, Seo JH, et al. Postanaesthetic emergence agitation in adult patients after general anaesthesia for urological surgery. J Int Med Res 2015; 43: 226-35.

5. Kim HC, Lim SM, Seo H, Park HP. Effect of glycopyrrolate versus atropine coadministered with neostigmine for reversal of rocuronium on postoperative catheter-related bladder discomfort in patients undergoing transurethral resection of bladder tumor: a prospective randomized study. J Anesth 2015; 29: 831-5.

6. Yoshida M, Homma Y, Inadome A, Yono M, Seshita H, Miyamoto $\mathrm{Y}$, et al. Age-related changes in cholinergic and purinergic neurotransmission in human isolated bladder smooth muscles. Exp Gerontol 2001; 36: 99-109.

7. Naguib M. Sugammadex: another milestone in clinical neuromuscular pharmacology. Anesth Analg 2007; 104: 575-81.

8. Lim N, Yoon H. Factors predicting catheter-related bladder discomfort in surgical patients. J Perianesth Nurs 2017; 32: 400-8.

9. Yu D, Chai W, Sun X, Yao L. Emergence agitation in adults: risk factors in 2,000 patients. Can J Anaesth 2010; 57: 843-8.

10. Agarwal A, Dhiraaj S, Pawar S, Kapoor R, Gupta D, Singh PK. An evaluation of the efficacy of gabapentin for prevention of catheter-related bladder discomfort: a prospective, randomized, placebo-controlled, double-blind study. Anesth Analg 2007; 105: 1454-7.

11. Rogers E, Mehta S, Shengelia R, Reid MC. Four strategies for managing opioid-induced side effects in older adults. Clin 
Geriatr 2013; 21(4). http://ncbi.nlm.nih.gov/pmc/articles/ PMC4418642/pdf/nihms667986.pdf.

12. Sanger GJ, Andrews PLR. A history of drug discovery for treatment of nausea and vomiting and the implications for future research. Front Pharmacol 2018; 9: 913.

13. Zhou L, Zhou L, Tian L, Zhu D, Chen Z, Zheng C, et al. Preoperative education with image illustrations enhances the effect of tetracaine mucilage in alleviating postoperative catheter-related bladder discomfort: a prospective, randomized, controlled study. BMC Anesthesiol 2018; 18: 204.

14. Hwang BY, Kwon JY, Jeon SE, Kim ES, Kim HJ, Lee HJ, et al. Comparison of patient-controlled epidural analgesia with patient-controlled intravenous analgesia for laparoscopic radical prostatectomy. Korean J Pain 2018; 31: 191-8. 